\title{
A Review of the Pharmacist as Vaccinator
}

Willis M. Richardson, PharmD; Albert I. Wertheimer, PhD, MBA

Temple University School of Pharmacy

\begin{abstract}
Objective: The aim of this study is to review literature about how the pharmacist's role as vaccination providers has been financially and clinically measured.

Methods: A broad literature search was conducted up to May 2016 to identify economic or clinical data on pharmacy vaccinations. MEDLINE ${ }^{\circledR}$ and PUBMED databases were searched for publications useful or potentially useful for this review. The NIH and CDC websites were also searched for relevant materials. Search terms included vaccination, pharmacist, economic, pharmacoeconomics, cost, benefits cost-effectiveness, physicians, immunizations, vaccinations, pharmacy vaccines, cost, physician vaccines, financial, benefit, ambulatory pharmacist vaccination, clinical pharmacist, economics, pharmacist vaccine impact.

Results: The search yielded a total of 68 articles of which 12 met the criteria to be included in this review. After examining articles for relevance to pharmacy vaccinations, two tables were created to highlight the clinical and economic advantages of the pharmacist as a vaccinator.

Conclusion: Pharmacists who administer vaccines are an underutilized provider. This literature review reveals a pattern among studies measuring the pharmacist's impact on vaccination rates, patient preferences, and cost savings. Pharmacists have a history of demonstrated dependability, accuracy, and cost effectiveness. State laws, collaborative agreements, and health plans have continued to prevent patients from using the pharmacy to receive the CDC recommended vaccines. These barriers ultimately delay the Healthy People 2020 goals.
\end{abstract}

\section{Introduction/Background}

Increasing vaccination rates to reduce infectious diseases remains one of the Healthy People 2020 objectives set forth by the United States Office of Disease Prevention and Health Promotion. ${ }^{1,2}$ Vaccine innovation and increased vaccination rates were linked with increased survival in the $20^{\text {th }}$ century. However, certain infectious diseases that can be prevented by vaccines, still remain a major cause of morbidity and mortality. ${ }^{2}$ Currently there are 17 vaccine-preventable diseases in the United States ${ }^{1}$, including influenza. Although preventable, influenza is one of the leading infections in the United States and accounts for substantial spending on the consequences associated with the virus. ${ }^{2}$

Vaccines remain the most cost-effective intervention in clinical prevention of infectious disease and their proper use is essential. ${ }^{2}$ Specifically, children's vaccination programs yield a higher return on investment. Children receiving their vaccinations according to the CDC schedule saves 33,000 lives, prevents 14 million instances of disease, reduces health care cost by $\$ 9.9$ billion, and saves $\$ 33.4$ billion in indirect cost. In spite of the available vaccines, about 42,000 of adults and 300 children die each year from vaccine preventable diseases. ${ }^{2}$

The pharmacists' role as vaccinators dates back to the 1800's. The first organized formal vaccination training for pharmacists

Corresponding Author: Willis M. Richardson, PharmD

Temple University School of Pharmacy

3307 N. Broad Street, Philadelphia, PA 19140

Email: willis.richardson@temple.edu took place in Seattle, Washington in 1994. In November 1996, the American Pharmacists Association began its nationally recognized training program for pharmacists; Pharmacy-Based Immunization Delivery: A National Certificate Program for Pharmacists. Today, pharmacists have authority to administer vaccines in all 50 states, including the District of Columbia and Puerto Rico. ${ }^{3}$

Pharmacists are immunization advocates and act as educators, facilitators, and vaccinators. ${ }^{4}$ Pharmacists provide education that helps dispel the many myths concerning vaccinations that dissuade the public from receiving them. Among the myths are vaccinations' link to autism, vaccinations cause sudden infant death syndrome, vaccines contain harmful ingredients that can affect children, vaccines cause neurological conditions (i.e., seizures), children are given excessive vaccines in a short period of time, and vaccines are derived from aborted fetuses. ${ }^{4}$

Pharmacists are trained to deliver adult vaccines, child vaccines and travel vaccines, but vaccination services are often subject to state legislation and physician protocols. State restrictions limit pharmacists from vaccinating patients in need by dictating the types of vaccines administered, the age of patients, type of order requiring a prescription, and standing order protocols. ${ }^{4}$ However, these restrictions have been suspended in times of pandemics, such as the H1N1 influenza, when additional vaccinators were needed. ${ }^{5}$ Additionally, the community pharmacy is equipped to deliver vaccines. The pharmacy has proper refrigeration, documentation, and emergency supplies. The pharmacy often has a private area for vaccine administration, which is useful for patient monitoring in case of allergic reactions. 
A pharmacist offers significant clinical and financial benefits through vaccination services. Administering vaccines in a community pharmacy has become accepted by the public, especially for influenza vaccine. Commercial and governmental health plans are beginning to provide coverage for those patients receiving vaccinations at pharmacy locations. However, health plans stipulate vaccine coverage and may not always pay for all recommended vaccines. ${ }^{6}$ The aim of this study is to review literature where the pharmacist as a vaccinator, has been financially and clinically assessed.

\section{Objectives}

The objectives for this review were to examine studies where the pharmacists served as a vaccinator and to document the clinical and financial impacts.

\section{Methods}

A broad literature search was conducted to identify economic and clinical data on pharmacists vaccinating in pharmacies. MEDLINE', PUBMED, NIH, and CDC databases were searched for publications useful or potentially useful in this collection of data. Search terms included vaccination, pharmacist, economic, pharmacoeconomics, cost, benefits cost-effectiveness, physicians, immunizations, vaccinations, pharmacy vaccines, cost, physician vaccines, financial, benefit, ambulatory pharmacist vaccination, clinical pharmacist, economics, pharmacist vaccine impact. Articles found were examined for relevance and a data table was created outlining areas where additional research is needed.

\section{Results}

The data examined in the literature review can be found in Tables 1 and 2 . The following are modified key points from the original article.

\section{Vaccinations Administered During Off-Clinic Hours at a National Community Pharmacy: Implications for Increasing Patient Access and Convenience: ${ }^{7}$}

- Researchers retrospectively reviewed data for all vaccinations administered at Walgreens pharmacies between August 2011 and July 2012. Specifically comparing between two time periods (standard clinic hours [9:00 am - 6:00 pm] and off-clinic hours), they analyzed the type of vaccine given as well as patient populations in order to assess implications for access and convenience.

- The following groups were most likely to be vaccinated during off-clinic hours: younger patients, patients living in metropolitan/micropolitan areas, patients living in states that allow pharmacists to administer all CDC-recommended vaccines, those receiving travel vaccines, and patients who receive $\geq 2$ vaccines in one year; this study found no difference in off-clinic hour use in patients who used the pharmacy for only vaccination vs those who were also picking up prescription.

- Vaccines with the greatest proportion administered during off-clinic hours were typhoid (41.5\%), Tdap (34.5\%), HPV (33.8\%), varicella zoster (31.6\%), influenza (31.5\%), hepatitis (31.4\%), and yellow fever (30.8\%).

- More than 1 million vaccinations took place during lunch hours (11:00 am to $1: 00 \mathrm{pm}$ ) out of total vaccinated administered of $6,250,402$.

- The proportion vaccinated during off- clinic hours was similar for patients with or without chronic conditions.

- More than 150,000 vaccinations occurred during the overnight hours of $10: 00 \mathrm{pm}$ to 9:00 am.

\section{Community Pharmacist-Administered Influenza Immunization} Improves Patient Access to Vaccines: ${ }^{8}$

- Research pharmacists collected survey data from 4 different community pharmacy locations in Toronto from October 2013 to November 2013 in order to describe demographics and possible patient risk factors for receiving the influenza vaccine in a community setting. The study also assesses patient experiences and perceptions.

- Convenience of the pharmacist is a major factor to patient satisfaction.

- $99 \%$ of surveys (1502 surveys total) indicated patients would recommend family and friends to be vaccinated by a pharmacist.

- One-third indicated that they would not have been vaccinated this year if pharmacist-administered vaccination were not available.

- No patient was dissatisfied with the vaccination provided by the pharmacist, pharmacy service, and injection technique. Rather, all patients surveyed were satisfied or very satisfied with pharmacy service and injection technique.

- All patients were either very comfortable or comfortable with their vaccine being administered by the pharmacist.

The Effect of Pharmacist Intervention on Herpes Zoster Vaccination in Community Pharmacies: ${ }^{9}$

- In this prospective intervention study, patients presenting to independent pharmacies across Tennessee were asked to complete a survey after receiving their vaccination. The survey aimed to capture patients' comfort level, sources of vaccination education and sources of influence. Questions such as, "How did you hear about the Shingles vaccine?" required patients to select from the following options: doctor, family/friend, pharmacist, flyer from your pharmacy, newspaper, letter in the mail from pharmacy and other. 
- The most effective method of pharmacy-driven intervention was the personalized letter.

- Patients were more likely to receive a vaccine from reading pharmacy-driven interventions than by influences from a physician $(P<0.0001)$, family/friend source $(P<0.0001)$, or other source $(P<0.0001)$.

- Of the 205 patients, 204 indicated they were very comfortable or somewhat comfortable with vaccines delivered by the pharmacist.

- When asked, "Why did you decide to get vaccinated against shingles?" There was no statistical difference between pharmacy-based sources and family/friends $(P=0.1025)$.

"It's Easier in Pharmacy": Why Some Patients Prefer to Pay for Flu Jabs Rather Than Use the National Health Service: ${ }^{10}$

- Retrospective data was collected in England during the 2012-2013 flu season to assess why patients eligible for free vaccination through the National Health Service (NHS) opted to pay privately. A total of 479 pharmacies provided data. Thirteen private service pharmacies were selected to further identify reasons for choosing to pay privately. They consisted of the top 100 performing pharmacies and 921 patients who had a vaccination were approached with a questionnaire.

- Of the 921 patients, 199 (22\%) were eligible for free vaccination and 100 chose not to use the free, NHS option. Primary reason was due to the inconvenience of going to a general practitioner.

- Other reasons for visiting a pharmacy for a flu vaccination included: location/hours convenience, pharmacy/staff environment preference, in-store advertisement, and vaccine availability.

- Reasons given for not visiting a general practitioner to get a flu vaccination: inconvenience of getting to the physician office (i.e., GP surgery), difficulty in scheduling an appointment, and unavailability of vaccines.

Who Uses Pharmacy for Flu Vaccinations? Population Profiling Through a UK Pharmacy Chain: ${ }^{11}$

- Pharmacists asked patients who received a vaccination between October 2014 and March 2015 to complete a questionnaire. Data was electronically recorded for 150, 997 vaccinations across 1,201 pharmacies in England. Typically, the pharmacy is accessible by frontline healthcare workers and people of working age from various demographic areas.

- Every patient cited convenience or accessibility as the primary reason for why they chose to receive their flu vaccination from a pharmacy, regardless of whether it was NHS or privately funded.
- The majority (85.6 \%) of all flu vaccinations were recorded between 9 am and $5 \mathrm{pm}$ with peaks occurring between $11 \mathrm{am}$ and $1 \mathrm{pm}$ (24.0\%).

Individual-and Neighborhood-Level Characteristics Associated With Support Of In-Pharmacy Vaccination Among ESAP-

Registered Pharmacies: Pharmacists' Role in Reducing Racial/ Ethnic Disparities in Influenza Vaccinations in New York City: ${ }^{12}$

- Using the Pharmacies as Resources Making Links to Community Services (PHARM-Link) community-based, randomized pharmacy-intervention study in New York, 477 pharmacy staff registered with the Expanded Syringe Access Program (ESAP) in Harlem, Lower Manhattan, the Bronx, Brooklyn and Queens were asked to complete a survey in order to assess support of in-pharmacy vaccinations. Survey question was "How much do you support vaccination services being provided in your pharmacy?"

- Pharmacies in neighborhoods with a high percent of minority residents were significantly less likely (PR, $0.94 ; 95 \% \mathrm{Cl}, 0.88-1.00, \mathrm{p}=0.0468$ ) to support inpharmacy vaccination compared with those with fewer minorities.

- Pharmacies in neighborhoods with more foreign-born residents were marginally more likely to support inpharmacy vaccination (PR, 1.06; 95\% Cl 0.99-1.13, $\mathrm{p}=0.0854$ ).

- This study found that pharmacy staff support of inpharmacy vaccination services was high overall $(86 \%$ of 437 surveyed).

- Initiatives are needed to increase knowledge about the importance of lower vaccination rates as well as increased influenza-related mortality among pharmacy staff and residents working in minority neighborhoods to help boost interest of in-pharmacy vaccinations in these specific communities.

\section{The Role of Pharmacists in the Delivery of Influenza Vaccinations: ${ }^{13}$}

- This study was a secondary analysis of the Behavioral Risk Factor Surveillance System (BRFSS) that was conducted in 1995 and 1999.

- In states where pharmacists are allowed to provide vaccinations, both individuals aged $18-64$ years (odds ratio $(O R)=1.27$; $95 \%$ confidence interval $(\mathrm{Cl})=1.19$ 1.36) and individuals aged 65 years and older $(O R=$ $1.22 ; 95 \% \mathrm{Cl}=1.07-1.39$ ) were more likely to receive influenza vaccines than individuals in states where pharmacists cannot provide vaccinations.

- Individuals who were Black or had a self-perceived cost barrier to receiving health care had a decreased likelihood of receiving vaccinations in both age categories. 
Pharmacists as Providers: Targeting Pneumococcal

Vaccinations to High-Risk Populations: ${ }^{14}$

- Between August 1, 2010 and November 14, 2010, a total of 2,095,748 patients received influenza vaccinations at Walgreens. At the same time of the flu vaccine, the pharmacist also recommended the PPSV23 if any risk was identified. Of the total study population, 1,343,751 (64\%) persons were considered at-risk and met the ACIP recommendation for PPSV23.

- 921,624 patients (69\%) were at-risk because they were age 65 and older; 22,127 patients (31\%) were at risk because they had one of the ACIP comorbid conditions and were aged 2-64.

- Pharmacists were especially effective at reaching patients aged 60-70 years, who are likely to be at-risk not only due to age but also due to comorbid conditions. Patients aged $60-70$ years had the highest PPSV23 vaccination rate $(6.60 \%, 26,430 / 400,454)$ of any age group.

Improved Influenza Vaccination Rates in a Rural Population as a Result of a Pharmacist-Managed Immunization Campaign: ${ }^{15}$

- In 1999, a pharmacy team conducted a manual chart review of 2,271 charts in a rural primary care clinic and collected patient demographic data including influenza vaccine history and influenza contraindications. They identified 657 patients who had indications for the vaccine. The team also developed education packets, which were distributed to the patients identified in the chart review. Vaccinations were given in specially designated clinics and during routine clinic visits. Campaign success and reasons why patients remained unvaccinated were determined by follow-up surveys.

- A total of 283 patients completed a survey designed to capture factors that convinced and reminded patients to get their vaccination. Of these, 199 respondents were patients with positive indications who were vaccinated against influenza and had received the education packet.

- This study demonstrated that this pharmacy-directed program significantly increased vaccinations by $95 \%$ for a group of high-risk patients in a rural community practice.

- Patients consistently identified the mailed education packet and their health care provider as the top factors that had convinced and reminded them to get vaccinated.

- The most common suggestions for improving the vaccination program included providing more days and times available for vaccine administration and increasing the staff to administer vaccinations.
Impact of Pharmacist Integration in a Pediatric Primary Care Clinic on Vaccination Errors: A Retrospective Review: ${ }^{16}$

- At the Nationwide Children's Hospital in Columbus, Ohio, vaccine error rates and missed opportunities were compared between two pediatric primary care clinics during April, May, and June 2011. Staffing levels were consistent throughout both clinics and included attending physicians and resident physicians, however, different individuals would staff each clinic. Specifically, the "intervention clinic" had a full-time, board-certified ambulatory clinical pharmacist who provided vaccination education to provider and patients. The "comparison clinic" did not include pharmacy personnel to ensure appropriate use of vaccines.

- After researchers reviewed 900 total randomized encounters from both clinics, 19 errors were found in the evaluation. With 2 errors identified in the comparison clinic and 17 from the "intervention clinic," the error rate was $0.28 \%$ and $2.7 \%$, respectively $(P=0.0021)$.

- Further research of pharmacist involvement in several areas of vaccine use is needed. This study did not include an economic evaluation of improved use of vaccines. Additional research investigating the economic implications of pharmacist integration into the primary care setting on vaccine use is also needed.

- Missed opportunities were defined as vaccine doses due at date of encounter and not given. In the comparison clinic, 132 randomized encounters were found to have greater than or equal to one missed opportunity, compared with 46 randomized encounters in the intervention clinic $(P<0.0001)$.

- Hepatitis $A$ vaccine and Hepatitis $B$ vaccine were the most common vaccines associated with missed opportunities.

Costs of Adult Vaccination in Medical Settings and Pharmacies: An Observational Study: ${ }^{17}$

- The objective of this observational retrospective study was to compare the direct costs paid in different settings (i.e., physician offices, other medical settings, and pharmacies) for adult vaccinations of zoster, pneumococcal, and influenza.

- The costs paid for vaccination-included costs associated with the vaccine product, administration, dispensing, and outpatient visit fees. Visit fees for medical settings were included only in those instances where vaccination was determined to be the trigger for the visit, i.e., the only service provided during the visit ( $\leq 2 \%$ of instances).

- Patients' mean (SD) ages across settings were 65.8 (6.7) years for zoster vaccine, 58.2 (12.2) years for pneumococcal vaccine, and 51.4 (13.8) years for influenza vaccine. 
- The mean (SD) total costs, which included health plan and enrollee payment, per vaccine administration at physician offices, other medical settings, and pharmacies were as follows:

o Physician offices: zoster vaccine- $\$ 208.72$

(42.10), pneumococcal vaccine $-\$ 65.69$ (27.54), and influenza vaccine $-\$ 29.29$ (15.29)

$(P<0.05)$.

$\circ$ Other medical settings (i.e., inpatient and outpatient hospital, emergency department): zoster vaccine $-\$ 209.51$ (50.83), pneumococcal vaccine $-\$ 72.11$ (49.95), and influenza vaccine $-\$ 24.20(13.12)(P<0.05)$.

o Pharmacies: zoster vaccine-\$168.50 (15.66), pneumococcal vaccine $-\$ 54.98(9.72)(P<0.05)$, influenza vaccine $-21.57(6.63)(P<0.05)$.

- The data may help payers and policymakers understand the economic value of adult vaccination in different settings, especially in pharmacies.

- For all 3 vaccines, the costs paid were significantly lower in pharmacies than in either physician offices or other medical settings $(P<0.05)$.

- For zoster vaccination, patients paid the least out-ofpocket at physician offices (\$16.95 [43.85], $P<0.05$ ), whereas insurers paid the least at pharmacies $(\$ 145.72$ [\$38.54], $P<0.05)$.

- For both the pneumococcal and influenza vaccines, patients paid the least at pharmacies, while insurers paid the least in other medical settings, and the most at physician offices.

- For zoster vaccination, patients paid the least out-ofpocket at physician offices, whereas insurers paid the least at pharmacies.

- From the patient perspective, costs paid were lower in pharmacies than in other medical settings for all 3 vaccinations and lower than in physician offices for pneumococcal and influenza vaccines.

- Researchers conducted telephone interviews with representatives from each setting in 2004 to understand the costs of vaccination delivery in nontraditional settings. They found that vaccination delivery cost less in the nontraditional settings ( $\$ 17$ in mass vaccination settings, $\$ 12$ in pharmacies) compared with physician offices (\$29). Additionally, they found that vaccination in nontraditional settings was projected to be cost saving for healthy adults aged $\geq 50$ years and for high-risk adults of all ages.

- Pharmacies had lower average direct costs paid per adult vaccination than physician offices and other medical settings-by $16 \%-26 \%$ and $11 \%-20 \%$, respectively-when both health plan and enrollees' perspectives were considered.
Non-Traditional Settings for Influenza Vaccination of Adults: Costs And Cost Effectiveness: ${ }^{18}$

- Using detailed phone interviews, researchers evaluated the costs of influenza vaccination in nontraditional settings. Target age population included 18-49, 50-64, and $\geq 65$ years with either high risk or low risk for influenza-related complications. Probability, direct costs, and opportunity costs were derived from primary data, unpublished and published sources.

- The mean total cost (US\$, year 2004 values) per vaccination, not including time cost, was estimated as \$11.57 for pharmacies, \$17.04 for mass vaccination clinics, and $\$ 28.67$ at doctor's office.

- The mean waiting time for mass vaccination and pharmacy clinics was 12 minutes for both; the doctors waiting time was over 1 hour.

- The reported mean cost per vaccine dose ranged from $\$ 7.48$ in the pharmacy setting to $\$ 9.24$ in the doctor's office.

- The patients' time, labor, and overhead cost were higher in scheduled doctor visits.

\section{Discussion}

Pharmacists administering vaccines has effectively lowered health care cost and increased vaccination rates. The data compiled in this review has revealed ways pharmacists have been using their practice to advance the promotion and administration of the CDC recommended vaccinations. Pharmacists offer education, advertising, and incentives to reach patient populations in need of vaccinations. Pharmacies also have various conveniences such as extended hours, shortened wait times, ease of access for medically underserved patients in urban and rural areas, and reduced vaccination costs. ${ }^{9-12,15}$ With $93 \%$ of Americans living within 5 miles of a community pharmacy, community pharmacists are one of the most readily accessible health care professionals in the United States. ${ }^{5}$

The clinical data collected has shown that pharmacy convenience and public trust as a vaccinator group is not a unique characteristic of pharmacists in the United States. ${ }^{10,11}$ Many patients in the UK preferred to pay the pharmacist for an influenza vaccination instead of receiving it for free from their general practitioner. ${ }^{10,11}$ Several studies demonstrate that many patients in the UK and United States go to the pharmacy during lunch hours. ${ }^{7,10,11}$ Convenience is arguably the most advantageous characteristic of pharmacies as a vaccination location. In addition, many pharmacies are open 24 hours including holidays, allowing patients to receive vaccinations during these off-clinic hours. ${ }^{7}$

Despite the convenience, various barriers such as state laws, collaboration protocols, and health plan restrictions further prevent pharmacies from administering the full CDC recommend schedule. An estimated 40,000 to 50,000 adults 
die annually from vaccine-preventable disease in the United States. ${ }^{5}$ Additionally, $\$ 10$ billion dollars are used to treat patients without routine or recommended vaccinations. ${ }^{5}$ The state laws restricting pharmacists as a vaccinator are inconsistent and seemingly arbitrary (Table 3). Many state laws prevent pharmacists from providing vaccinations to the most cost-effective population-children. Some states limit the pharmacist to certain types of vaccines. The 2016 ACPE accreditation standards for the doctor of pharmacy curriculum requires pharmacy schools to provide training for students to become certified in administering injections. ${ }^{21}$ Furthermore, biologics and vaccines are considered pharmaceutical products approved through the FDA, which positions pharmacists as vaccine experts. The expertise provided by pharmacists was demonstrated in Haas-gehres a, et al. where pharmacy interventions significantly decreased missed opportunities for scheduled vaccinations. ${ }^{16}$ Vaccination protocols, prescription only orders and standing orders are additional barriers to patient access to pharmacy service. Also, both commercial and state health plans do not readily cover all scheduled vaccines ${ }^{5}$ when administered in the pharmacy setting, further hindering healthcare. With the inconsistent restrictions and lack of medical standard, research concerning protocols and orders would assist in determining the practicality of these restrictions.

Economically, vaccines delivered in the pharmacy lower the cost for health care. ${ }^{17,18}$ Patients have higher direct and opportunity costs when getting vaccinations at their physician's office. ${ }^{18,19}$ A recent study has shown the average opportunity cost per physician visit was $\$ 43$, which exceeds the average patient's out-of-pocket payment. Total opportunity costs per year for all physician visits in the United States were $\$ 52$ billion in 2010. ${ }^{19}$ Studies have shown that receiving vaccines in the pharmacy setting was the least expensive option for patients. In contrast, vaccines delivered in the traditional physical office setting are the most expensive. ${ }^{17,18}$ The patient may also experience opportunity costs due to office wait times or appointment co-pays. ${ }^{17-19}$ Compounding the inconveniences of going to a physician office has made many patients appreciate the prompt service in the pharmacy setting. Additional electronic technologies within pharmacy software systems have enabled pharmacists to identify risk groups in need of vaccinations. Researchers have conducted a study using claims data as an identifying tool. ${ }^{14}$ Moreover, patients visit their pharmacies more frequently, thus facilitating the verification of vaccine history and minimizing missed opportunities.

After reviewing the literature, pharmacy practice should enhance the pharmacist's role as a vaccinator by including complete vaccination records with the patient's medication profile. The community pharmacy serves as a valuable source of history for each patient's prescriptions records, and adding the vaccination history to the patient profile will help identify those who have not received their recommended vaccinations according to the CDC guidelines. The vaccination history developed by the pharmacist will also serve as a tool to assist various medical personnel involved with the patient. Also, insurance companies should extend pharmacy insurance benefits to cover vaccines as a preventative pharmaceutical measure against disease. Expanding vaccines coverage in the pharmacy setting will bring current those who are irregularly vaccinated and increase vaccination rates in hard-to-reach populations. $^{12}$

The following are research proposals that can measure the clinical and economic impact of the pharmacist as a vaccinator: comparisons of direct cost and opportunity cost for the full vaccination schedule administered at the community pharmacy vs. the physician's office, cost effectiveness of travel vaccines given in a community pharmacy setting, a study to determine or estimate the average number of vaccinations a pharmacy administers annually, an observational claims analysis of rejected vaccinations by an insurance provider in the community setting, and a literature review of pharmacy protocols and state law limitations.

\section{Conclusion}

Pharmacists as vaccinators are an underutilized vaccine provider source. This literature review reveals a pattern among studies measuring pharmacists' impact on vaccine rates, patient preferences, and cost savings. Expanding the pharmacists' ability to vaccinate more population groups through the changing legislation has traditionally increased vaccination rates by state. ${ }^{13}$ Inconsistency exists within the health benefits system, which complicates pharmacy vaccination efforts. Vaccination is the most cost effective way to prevent infectious disease and comorbid complications, however commercial and governmental health plans provide limited coverage for receiving vaccinations from a pharmacy. ${ }^{5}$ Pharmacists have demonstrated to be dependable, accurate, and cost effective vaccination providers. State laws, collaborate agreement protocols, and health plans have prevented patients from using the pharmacy to receive all CDC recommended vaccines which can potentially delay the Healthy People 2020 goal of increasing vaccination rates and reducing preventable infectious diseases.

Acknowledgements: Thank you Dr. Albert Wertheimer for the opportunity to conduct this research and encouraging me to have our work published.

Conflict of Interest: We declare no conflicts of interest or financial interests that the authors or members of their immediate families have in any product or service discussed in the manuscript, including grants (pending or received), employment, gifts, stock holdings or options, honoraria, consultancies, expert testimony, patents and royalties. 


\section{References}

1. Centers for Disease Control and Prevention (CDC). Achievements in public health, 1900-1999: Control of infectious diseases. MMWR. 1999 Jul 30;48(29):621-9

2. Immunization and Infectious Diseases. (n.d.).

Retrieved March 12, 2016, from https://www.healthypeople.gov/2020/topicsobjectives/topic/immunization-and-infectiousdiseases\#star

3. APhA. Pharmacists play a vital role in providing immunizations in their communities. http://www.pharmacist.com/AM/Template.cfm? Section=News_Releases2\&template $=/ C M /$ ContentDis play.cfm\&ContentID $=23001$.

4. Weidman-Evans E, Mohundro B.L. (2013). Chapter 6. Immunization Services. In Ellis A.W., Sherman J.J. (Eds), Community and Clinical Pharmacy Services: A Step-by-Step Approach. Retrieved April, 2016 from http://accesspharmacy.mhmedical.com.libproxy.tem ple.edu/content. aspx ?bookid $=684 \&$ Sectionid $=451458$ 41

5. Events FO, Policy BO, Medicine IO. The 2009 H1N1 Influenza Vaccination Campaign: Summary of a Workshop Series. National Academies Press; 2010.

6. Bach, Albert and Jeffery Goad. "The Role of Community Pharmacy-Based Vaccination in the USA: Current Practice and Future Directions". IPRP (2015): 67. Web. 1 May 2016.

7. Goad JA, Taitel MS, Fensterheim LE, Cannon AE. Vaccinations administered during off-clinic hours at a national community pharmacy: implications for increasing patient access and convenience. Ann Fam Med. 2013;11(5):429-36

8. Papastergiou J, Folkins C, Li W, Zervas J. Community pharmacist-administered influenza immunization improves patient access to vaccination. Can Pharm J (Ott). 2014;147(6):359-65.

9. Wang J, Ford $L$, Wingate $L$, et al. Effect of pharmacist intervention on herpes zoster vaccination in community pharmacies. J Am Pharm Assoc (2003). 2013;53(1):46-53.

10. Anderson C, Thornley T. "It's easier in pharmacy": why some patients prefer to pay for flu jabs rather than use the National Health Service. BMC Health Serv Res. 2014;14:35.

11. Anderson C, Thornley T. Who uses pharmacy for flu vaccinations? Population profiling through a UK pharmacy chain. Int J Clin Pharm. 2016;38(2):218-22.

12. Crawford ND, Blaney S, Amesty $S$, et al. Individualand neighborhood-level characteristics associated with support of in-pharmacy vaccination among ESAP-registered pharmacies: pharmacists' role in reducing racial/ethnic disparities in influenza vaccinations in New York City. J Urban Health. 2011;88(1):176-85.
13. Steyer TE, Ragucci KR, Pearson WS, Mainous AG. The role of pharmacists in the delivery of influenza vaccinations. Vaccine. 2004;22(8):1001-6.

14. Taitel M, Cohen E, Duncan I, Pegus C. Pharmacists as providers: targeting pneumococcal vaccinations to high risk populations. Vaccine. 2011;29(45):8073-6.

15. Van amburgh JA, Waite NM, Hobson EH, Migden H. Improved influenza vaccination rates in a rural population as a result of a pharmacist-managed immunization campaign. Pharmacotherapy. 2001;21(9):1115-22.

16. Haas-gehres A, Sebastian S, Lamberjack K. Impact of pharmacist integration in a pediatric primary care clinic on vaccination errors: a retrospective review. J Am Pharm Assoc (2003). 2014;54(4):415-8.

17. Singhal $P K$, Zhang D. Costs of adult vaccination in medical settings and pharmacies: an observational study. J Manag Care Spec Pharm. 2014;20(9):930-6.

18. Prosser LA, O'brien MA, Molinari NA, et al. Nontraditional settings for influenza vaccination of adults: costs and cost effectiveness. Pharmacoeconomics. 2008;26(2):163-78.

19. Ray KN, Chari AV, Engberg J, Bertolet M, Mehrotra A. Opportunity costs of ambulatory medical care in the United States. Am J Manag Care. 2015;21(8):567-74.

20. NABP. Independent Pharmacy Practice. The 2016 Survey of Pharmacy Law. 2016

21. Accreditation council for pharmacy education. Accreditation standards and key elements for the professional program in pharmacy leading to the doctor of pharmacy degree ("Standards 2016"). Chicago, Illinois. 2015. 
Table 1: Clinical

\begin{tabular}{|c|c|c|c|c|}
\hline $\begin{array}{l}\text { Name of Study and } \\
\text { Description }\end{array}$ & Type of Study / Objectives & Methods & Results & Implications \\
\hline $\begin{array}{l}\text { Vaccinations } \\
\text { administered during } \\
\text { off-clinic hours. } \\
\text { Increasing patient } \\
\text { access and } \\
\text { convenience. }{ }^{7} \\
\text { Goad Ja et al. Ann } \\
\text { Fam Med. } \\
\text { 2013;11(5):429-36 }\end{array}$ & $\begin{array}{l}\text { Retrospective review. } \\
\text { Objective: Analyze the } \\
\text { types of vaccine } \\
\text { administered and patient } \\
\text { pharmacies population } \\
\text { vaccinated during off clinic } \\
\text { hours in a nationally } \\
\text { community pharmacy. }\end{array}$ & $\begin{array}{l}\text { One-year vaccination review } \\
\text { chain pharmacy. } \\
\text { Categorized by traditional } \\
\text { hours ( } 9 \text { am- } 6 \mathrm{~m} \text { ) vs. off clinic } \\
\text { hours (evening, holidays, } \\
\text { weekends). } \\
\text { Compared demographic and } \\
\text { types of vaccines. }\end{array}$ & $\begin{array}{l}\text { Pharmacist administered } \\
6,250,402 \text { vaccinations. } \\
30.5 \% \text { provided during off } \\
\text { clinic hours. } \\
\text { Patients had higher odds of } \\
\text { off-clinic vaccination if they } \\
\text { were younger than } 65 \text {, male, } \\
\text { reside in urban area, and did } \\
\text { not have chronic conditions. } \\
\text { 17.5\% of all vaccines } \\
\text { administered during lunch } \\
\text { hours (11 am -1 pm). } \\
\text { Patients are more likely to use } \\
\text { off clinic hours if they were } \\
\text { vaccinated in states that } \\
\text { authorize pharmacist to all } \\
\text { CDC-recommended vaccines } \\
\text { vs. states that authorize } \\
\text { pharmacist to administer } \\
\text { influenza, pneumonia and } \\
\text { zoster (OR = } 1.0044 ; 95 \% \mathrm{Cl} \text {, } \\
1.040-1.049 \text { ). }\end{array}$ & $\begin{array}{l}\text { The typical off clinic hour user, } \\
\text { male, young, heather patient, } \\
\text { reside highlighter more likely to } \\
\text { be vaccinated during off-clinical } \\
\text { hours. } \\
\text { Community pharmacies are } \\
\text { expanding the access and } \\
\text { convenience of vaccines. } \\
\text { Working population utilize the } \\
\text { convenience outside the } \\
\text { working hours thus increases } \\
\text { vaccination rates. } \\
\text { Patient seek vaccinations at } \\
\text { times most convenient to them. } \\
\text { Expanding the pharmacist ability } \\
\text { to administer adults and } \\
\text { children for all vaccines in all } \\
\text { states will have the greatest } \\
\text { impact on vaccination rates. }\end{array}$ \\
\hline $\begin{array}{l}\text { Community } \\
\text { pharmacist- } \\
\text { administered } \\
\text { influenza } \\
\text { immunization } \\
\text { improves patient } \\
\text { access to vaccines }{ }^{8} \\
\\
\text { Papastergiou J et al. } \\
\text { Can Pharm J (Ott). } \\
\text { 2014; 147(6):359-65 }\end{array}$ & $\begin{array}{l}\text { Objective: } \\
\text { To describe the } \\
\text { demographics of patients } \\
\text { receiving influenza vaccines } \\
\text { in the community setting } \\
\text { and to understand patient } \\
\text { perceptions of pharmacy } \\
\text { vaccinations. }\end{array}$ & $\begin{array}{l}\text { Survey collected at } 4 \\
\text { community pharmacy } \\
\text { locations in Toronto in 8- } \\
\text { week period. }\end{array}$ & $\begin{array}{l}1502 \text { surveys were collected. } \\
86 \% \text { of patient were very } \\
\text { comfortable or comfortable } \\
14 \% \text { with being vaccinated by } \\
\text { pharmacist. } \\
92 \% \text { of patients were very } \\
\text { satisfied or satisfied } 8 \% \text { with } \\
\text { pharmacies' service and } \\
\text { injection technique. } \\
28 \% \text { of patients indicated that } \\
\text { they would not have been } \\
\text { vaccinated that year if the } \\
\text { pharmacy service were not } \\
\text { provided. } \\
46 \% \text { of the patients had risk } \\
\text { factors such as heart disease, } \\
\text { respiratory disease, cancer, } \\
\text { diabetes or was receiving } \\
\text { immunosuppressant. }\end{array}$ & $\begin{array}{l}\text { Pharmacist have the potential to } \\
\text { provide a positive effect on } \\
\text { public health by improving } \\
\text { vaccination rates among high } \\
\text { risk patients and first time } \\
\text { vaccine recipients. } \\
\text { Expanding pharmacist } \\
\text { vaccination services to cover } \\
\text { other vaccines would improve } \\
\text { patient access and would } \\
\text { receive positive reception. }\end{array}$ \\
\hline
\end{tabular}




The effect of
pharmacist
intervention of
Herpes Zoster
Vaccination in
community practice9
Wang et al. J Am
Pharm Assoc (2003).
2013;53(1):46-53.

2013;53(1):46-53.
Prospective interventional

with pre-post design.

Investigate whether intervention by community pharmacist promoting herpes zoster would result in an increased rate.

Outcomes:

Primary: Compare vaccination rates for herpes zoster during the period control and intervention period and patients.

Secondary: evaluate relative efficacy of the pharmacy intervention two areas: educating patients about vaccine and influence patients to receive vaccine.
Study of three pharmacies that serve suburban, semirural, rural demographics.

Two protocols: collaborative practice and $R x$ all vaccines Control period, patients who voluntary presented to pharmacy requesting herpes zoster vaccination. 4 weeks.

Intervention period, release of newspaper press containing information on herpes zoster, every script dispense contained herpes zoster flyer, all patients profiles with CDC ACIPrecommend indications were identified and a one-time personal letter was sent containing the same information from the press release and flyer. 4 weeks.
Vaccination rates increased from $0.37 \%$ (or $59 / 16,121$ ) during the control period to $1.20 \%$ (or $193 / 16,062$ ) during the intervention period $(P<0.0001)$.

The number of survey respondents was 158 while 193 individuals in pharmacy databases received the vaccine during the intervention period, giving a response rate over $80 \%$.

There was no statistical difference when pharmacybased sources and family/friends were compared $(P=0.1025)$.

Patients were more likely to be influenced to receive the herpes zoster vaccination as a result of one of the pharmacist - driven interventions rather than a physician $(P=0.0260)$ or other source $(P<0.0001)$.

The pharmacy-driven interventions, the personalized letter was more effective than all of the other interventions in influencing patients to receive the herpes zoster vaccine.

205 patients who filled out a survey during the study, 204 (99.5\%) reported being either very comfortable or somewhat comfortable with the pharmacist administering the vaccine.

Pharmacy sources were generally statistically more effective than were all other sources in educating people about the vaccine and influencing patients to receive the herpes zoster vaccination. The only exception was that there was no difference in efficacy of pharmacy sources and family members or friends in influencing patients to receive the vaccine.
Pharmacists can attain better vaccine outcomes by communication with patients using mediums as personal letters.

Pharmacists are a well-trusted source for vaccination information. 
It's easier in pharmacy": why some patients prefer to pay for flu jabs rather than use the National Health Service. ${ }^{10}$

Anderson Cet al. BMC Health Serv Res. 2014;14:35.
This paper discusses retrospective data collected through a sample of Boots UK community pharmacies during 2012-13 to help support the case for national commissioning of flu vaccinations through pharmacy.
Data were collected during

the 2012-13 flu season as

part of a community

pharmacy private flu

vaccination service to help

identify whether patients

were eligible to have their

vaccination free of charge on

the NHS. Additional data

were collected from a sample

of patients accessing the

private service within 13

pharmacies to help identify

the reasons patients paid

when they were eligible for

free vaccination.
Who uses pharmacy for flu vaccinations? Population profiling through a UK pharmacy chain ${ }^{11}$

Anderson C et al. Int J Clin Pharm. 2016;38(2):218-22
To understand the profile of people accessing flu vaccination services within a large pharmacy chain.

Retrospective data collected through a sample of in England during the 2014/15 Flu season.

\section{Pharmacists requested}

people who had been

vaccinated in 2014/15 to

complete a questionnaire.

Data was captured

electronically on vaccine

delivery levels across 1201

pharmacies. Deprivation

profiles were calculated using

the Carstairs index.

Carstairs index (used to

calculate deprivation

quintiles for least and most

deprived); based on four

census indicators: low social

class, lack of car ownership,

overcrowding, and male unemployment.

Individual- and Neighborhood-Level Characteristics Associated with Support of InPharmacy Vaccination among ESAP-Registered

Pharmacies:

Pharmacists' Role in Reducing

Racial/Ethnic

Disparities in

Influenza

Vaccinations

in New York City ${ }^{12}$

Crawford ND et al. J Urban Health. 2011;88(1):176-85.
New York State (NYS)

passed legislation authorizing pharmacists to administer vaccines in 2008. Racial/socioeconomic disparities persist in vaccination rates and vaccine-preventable diseases such as influenza. Many NYS pharmacies participate in the Expanded Syringe Access Program (ESAP), which allows provision of nonprescription syringes to help prevent transmission of HIV, and are uniquely positioned to offer vaccination services to lowincome communities. To understand individual and neighborhood characteristics of pharmacy
Used pharmacy staff baseline data to assess support of inpharmacy vaccination, which was measured using a Likert scale (very supportive, somewhat supportive, not supportive, don't know, and refused) in response to, "How much do you support vaccination services being provided in your pharmacy?" Persons who reported being very supportive or somewhat supportive were classified as supportive, and those who reported not supportive were classified as not supportive. Persons who reported don't know and refused were excluded from this analysis $(n=4)$. It is important to note that support of in-pharmacy vaccination reflects individual
Data were captured from 89,011 privately paying patients across 479 pharmacies in England, of whom 6\% were eligible to get the vaccination free. 921 patients completed a survey in the 13 pharmacies selected. Of these, 199 (22\%) were eligible to get their flu vaccination for free. 131 (66\%) were female. Average age was 54 years. Of the 199 patients who were eligible for free treatment, 100 (50\%) had been contacted by their GP surgery to go for their vaccination, but had chosen not to go. Reasons given include accessibility, convenience and preference for pharmacy environment. 1741 patients from a total of 55 pharmacies completed the survey. Convenience and accessibility remain the key reasons for attending pharmacy.

Pharmacy services are accessed by people from all postcode areas, including some from the most deprived localities.

Patients would rather pay for convenience than wait for long time for free service.

These services are highly accessed by patients from all socio demographic areas. Patients would rather pay for convenience than wait for long time for free service.

Health professionals and working class people tend to use the pharmacy vaccine service.

The sample consists of 437 pharmacists, non- pharmacist owners, and technicians enrolled from 103 eligible New York City pharmacies. Using multilevel analysis, pharmacy staff that expressed support of in- pharmacy vaccination services were $69 \%$ more likely to support in-pharmacy HIV testing services (OR, 1.69; 95\% Cl 1.39-2.04)

There was a total of 437

pharmacy staff: 189 pharmacists, 19 nonpharmacist owners/managers, and 229 pharmacy technicians/clerks. Of these pharmacy staff, $38.7 \%$ were male, most were Hispanic (36.1\%), followed by Asian/Pacific Islander (19.3\%), African American (18.2\%),
Evidence-supporting scale-up of vaccination efforts in pharmacies located in foreignborn/immigrant communities, which has potential to reduce disparities in vaccination rates and preventable influenzarelated mortality. The majority of pharmacy personnel are very supportive of in pharmacy vaccination despite sociodemographics disparities. Pharmacies that also offer other public health service are more likely to support in-pharmacy vaccinations.

Pharmacies are in the key position to vaccinate too-hardto-reach population groups. 


\begin{tabular}{|c|c|c|c|c|}
\hline & $\begin{array}{l}\text { staff support for in- } \\
\text { pharmacy vaccination, we } \\
\text { combined census tract data } \\
\text { with baseline pharmacy } \\
\text { data from the Pharmacies } \\
\text { as Resources Making Links } \\
\text { to Community Services } \\
\text { (PHARM-Link) study among } \\
\text { ESAP-registered } \\
\text { pharmacies. }\end{array}$ & $\begin{array}{l}\text { attitudes and beliefs of this } \\
\text { service rather than actual } \\
\text { participation in current } \\
\text { vaccination services in their } \\
\text { pharmacy. Participants were } \\
\text { probed about their level of } \\
\text { support even if this service } \\
\text { was not feasible in the } \\
\text { pharmacy. Therefore, we } \\
\text { refer to the reported beliefs } \\
\text { and attitudes of in-pharmacy } \\
\text { vaccination as in-pharmacy } \\
\text { vaccination support. }\end{array}$ & $\begin{array}{l}\text { White (13.1\%), South } \\
\text { Asian/Indian/Pakistani ( } 8.3 \%), \\
\text { and other race/ethnicity } \\
\text { (5.1\%). Pharmacy staff worked } \\
\text { an average of } 9.4 \text { years in } \\
\text { pharmacies. Most ( } 86.3 \%) \\
\text { pharmacy staff supported } \\
\text { vaccination being provided } \\
\text { inside the pharmacy. }\end{array}$ & \\
\hline $\begin{array}{l}\text { The role of } \\
\text { pharmacists in the } \\
\text { delivery of influenza } \\
\text { vaccinations }{ }^{13} \\
\text { Steyer TE et al. } \\
\text { Vaccine. } \\
2004 ; 22(8): 1001-6 \text {. }\end{array}$ & $\begin{array}{l}\text { The purpose of this study is } \\
\text { to determine whether } \\
\text { influenza vaccine rates } \\
\text { have increased in states } \\
\text { where pharmacists can give } \\
\text { vaccines. } \\
\text { To assess the impact of } \\
\text { legislation allowing } \\
\text { pharmacists to administer } \\
\text { vaccine. }\end{array}$ & $\begin{array}{l}\text { For this analysis, the } 1995 \\
\text { and } 1999 \text { Behavioral Risk } \\
\text { Factor Surveillance System } \\
\text { (BRFSS) was used. The BRFSS } \\
\text { is an annual telephone survey } \\
\text { conducted by the Centers for } \\
\text { Disease Control and } \\
\text { Prevention that assesses } \\
\text { health risks in the US. In this } \\
\text { survey, individuals are asked, } \\
\text { "During the past } 12 \text { months, } \\
\text { have you had a flu shot?" } \\
\text { Sixteen states were taken } \\
\text { from the BRFSS to compare } \\
\text { influenza vaccination rates } \\
\text { for individuals both } 18-64 \\
\text { and } 65 \text { years and older. Eight } \\
\text { of these states (Arkansas, } \\
\text { Kansas, Nebraska, North } \\
\text { Dakota, Oklahoma, } \\
\text { Tennessee, Texas and } \\
\text { Virginia) passed legislation in } \\
1997 \text { allowing pharmacists to } \\
\text { administer vaccines while } \\
\text { eight (Louisiana, Missouri, } \\
\text { lowa, Wyoming, Utah, West } \\
\text { Virginia, Florida, and } \\
\text { Maryland) had no legislation } \\
\text { prior to } 2000 . \text { Data for the } \\
\text { years } 1995 \text { and } 1999 \text { were } \\
\text { then analyzed. } \\
\text { Secondary analysis of the } \\
\text { Behavioral Risk Factor } \\
\text { Surveillance System (BRFSS) } \\
\text { from the years } 1995 \text { and } \\
\text { 1999. Information regarding } \\
\text { legislation allowing } \\
\text { pharmacists to administer } \\
\text { Association. }\end{array}$ & $\begin{array}{l}\text { Individuals aged } 65 \text { years and } \\
\text { older who lived in states where } \\
\text { pharmacists could provide } \\
\text { vaccines had significantly } \\
\text { higher }(P<0.01) \text { influenza } \\
\text { vaccine rates than individuals } \\
\text { of this age who resided in } \\
\text { states where pharmacists } \\
\text { could not provide vaccines. }\end{array}$ & $\begin{array}{l}\text { Allowing pharmacists to provide } \\
\text { vaccinations is associated with } \\
\text { higher influenza vaccination } \\
\text { rates for individuals aged } 65 \\
\text { years and older. } \\
\text { Expanding the pharmacies } \\
\text { ability to administer more } \\
\text { vaccines increases vaccination } \\
\text { rates in new populations. } \\
\text { Expanding patient access and } \\
\text { refining legal parameters in } \\
\text { pharmacy practice has a } \\
\text { correlated effect in the groups } \\
\text { who are vaccinated. }\end{array}$ \\
\hline
\end{tabular}




\begin{tabular}{|c|c|c|c|c|}
\hline $\begin{array}{l}\text { Pharmacists as } \\
\text { providers: Targeting } \\
\text { pneumococcal } \\
\text { vaccinations to high } \\
\text { risk populations }{ }^{14} \\
\text { Taitel M et al. } \\
\text { Vaccine. } \\
\text { 2011;29(45):8073-6. }\end{array}$ & $\begin{array}{l}\text { The objective of this study } \\
\text { was to evaluate the impact } \\
\text { of pharmacists educating } \\
\text { at-risk patients on the } \\
\text { importance of receiving a } \\
\text { pneumococcal vaccination. }\end{array}$ & $\begin{array}{l}\text { Using de-identified claims } \\
\text { from a large, national } \\
\text { pharmacy chain, all patients } \\
\text { who had received an } \\
\text { influenza vaccination } \\
\text { between August } 1,2010 \text { and } \\
\text { November 14, } 2010 \text { and who } \\
\text { were eligible for PPSV23 were } \\
\text { identified for the analysis. } \\
\text { Based on the Advisory } \\
\text { Committee on Immunization } \\
\text { Practices recommendations, } \\
\text { at-risk patients were } \\
\text { identified as over } 65 \text { years of } \\
\text { age or as aged 2-64 with a } \\
\text { comorbid conditions. A } \\
\text { benchmark medical and } \\
\text { pharmacy claims database of } \\
\text { commercial and Medicare } \\
\text { health plan members was } \\
\text { used to derive a PPSV23 } \\
\text { vaccination rate typical of } \\
\text { traditional care delivery to } \\
\text { compare to pharmacy-based } \\
\text { vaccination. Period incidence } \\
\text { of PPSV23 was calculated and } \\
\text { compared. }\end{array}$ & $\begin{array}{l}\text { Among the } 1.3 \text { million at-risk } \\
\text { patients, } 65,598(4.88 \%) \\
\text { received a pneumococcal } \\
\text { vaccine. This vaccination rate } \\
\text { was significantly }(p<.001) \\
\text { higher than the PPSV23 } \\
\text { benchmark rate of } 2.90 \% \\
(34,917 / 1,204,104) . \text { In the } \\
\text { study group, PPSV23 rates } \\
\text { varied by age group but not by } \\
\text { gender. Patients aged } 60-70 \\
\text { years had the highest } \\
\text { vaccination rate }(6.60 \%, \\
26,430 / 400,454) \text { of any age } \\
\text { group. }\end{array}$ & $\begin{array}{l}\text { Pharmacies have the ability to } \\
\text { target at risk vaccination groups. } \\
\text { Pharmacy electronic records can } \\
\text { filter patient profiles based on } \\
\text { risk factors characteristic. } \\
\text { Pharmacies can expand this } \\
\text { function to make more health or } \\
\text { vaccine interventions and } \\
\text { produce better outcomes for } \\
\text { patients. } \\
\text { These results support the } \\
\text { expanding role of community } \\
\text { pharmacists in the provision of } \\
\text { wellness and prevention } \\
\text { services. } \\
\text { Pharmacies can help achieve the } \\
\text { U.S. Department of Health and } \\
\text { Human Services' Healthy People } \\
\text { goals for vaccine coverage. This } \\
\text { study supports the expanding } \\
\text { role of community pharmacists } \\
\text { in the provision of wellness and } \\
\text { prevention services. }\end{array}$ \\
\hline $\begin{array}{l}\text { Improved Influenza } \\
\text { Vaccination Rates in } \\
\text { a Rural Population as } \\
\text { a Result of a } \\
\text { Pharmacist-Managed } \\
\text { Immunization } \\
\text { Campaign }{ }^{15} \\
\text { Van amburgh JA et } \\
\text { al. Pharmacotherapy. } \\
\text { 2001;21(9):1115-22. }\end{array}$ & $\begin{array}{l}\text { To increase the rate of } \\
\text { influenza vaccinations in } \\
\text { high-risk patients by means } \\
\text { of a pharmacist-managed } \\
\text { immunization campaign. } \\
\text { Unblinded, single } \\
\text { intervention. } \\
\text { Rural primary care clinic. }\end{array}$ & $\begin{array}{l}\text { The pharmacy team } \\
\text { developed an education } \\
\text { packet that was sent to all } \\
\text { patients who needed the } \\
\text { influenza vaccine. The packet } \\
\text { contained a letter and a two- } \\
\text { sided information insert } \\
\text { designed in collaboration } \\
\text { with a teaching/learning } \\
\text { specialist. } \\
\text { The pharmacy team } \\
\text { developed two surveys. One } \\
\text { survey, for patients who } \\
\text { received the influenza } \\
\text { vaccine (entitled "We helped } \\
\text { you, now you can help us"), } \\
\text { was given by a nurse or } \\
\text { pharmacist to patients during } \\
\text { the vaccination clinic, at } \\
\text { physician appointments, or } \\
\text { by mail. } \\
\text { A follow-up letter and survey } \\
\text { were mailed in early } \\
\text { December to unvaccinated } \\
\text { patients who had indications } \\
\text { for vaccine. The primary } \\
\text { focus was to encourage them } \\
\text { to get vaccinated if they had } \\
\text { not yet done so. }\end{array}$ & $\begin{array}{l}\text { Before intervention (1998), } \\
\text { vaccination rates were low: } \\
182(28 \%) \text { patients with and } \\
102(6 \%) \text { patients without } \\
\text { indications for the vaccine. } \\
\text { After the pharmacy-directed } \\
\text { intervention in } 1999,354 \\
\text { (54\%) patients with and } 148 \\
\text { (9\%) patients without } \\
\text { indications were successfully } \\
\text { vaccinated. } \\
\text { The influenza vaccination rate } \\
\text { increased from } 28 \% \text { at baseline } \\
\text { (before program initiation) to } \\
54 \% \text { after program initiation. } \\
\text { Unvaccinated patients were } \\
\text { younger and resided in more } \\
\text { urban areas than vaccinated } \\
\text { patients; vaccinated patients } \\
\text { had a higher frequency of } \\
\text { cardiovascular disease or } \\
\text { diabetes mellitus. Vaccinated } \\
\text { patients consistently identified } \\
\text { the education packet and their } \\
\text { health care providers as } \\
\text { primary motivators for } \\
\text { vaccination. } \\
\text { Total of } 283 \text { patients } \\
\text { completed the "We helped } \\
\text { you, now you can help us" } \\
\text { survey. Of these, } 199\end{array}$ & $\begin{array}{l}\text { This study demonstrated that } \\
\text { this pharmacy- directed } \\
\text { program, which included a } \\
\text { mailing and improved access to } \\
\text { the influenza vaccine, } \\
\text { significantly increased } \\
\text { vaccinations by } 95 \% \text { for a group } \\
\text { of high-risk patients in a rural } \\
\text { community practice. } \\
\text { The education packet received } \\
\text { by mail was the most common } \\
\text { reason patients were both } \\
\text { convinced and reminded to get } \\
\text { vaccinated. }\end{array}$ \\
\hline
\end{tabular}




\begin{tabular}{|c|c|c|c|c|}
\hline & & & $\begin{array}{l}\text { respondents were patients } \\
\text { with positive indications who } \\
\text { were vaccinated against } \\
\text { influenza and had received the } \\
\text { education packet ( } 56.4 \% \\
\text { response rate). Patients } \\
\text { consistently identified the } \\
\text { mailing and their health care } \\
\text { provider as the top factors that } \\
\text { had convinced and reminded } \\
\text { them to get vaccinated. } \\
\text { The most common suggestions } \\
\text { for improving the vaccination } \\
\text { program were to provide more } \\
\text { days and times available to be } \\
\text { vaccinated and to increase the } \\
\text { number of providers to } \\
\text { administer vaccinations. }\end{array}$ & \\
\hline $\begin{array}{l}\text { Impact of pharmacist } \\
\text { integration in a } \\
\text { pediatric primary } \\
\text { care clinic on } \\
\text { vaccination errors: A } \\
\text { retrospective }_{\text {review }^{16}} \\
\text { Haas-gehres A. J Am } \\
\text { Pharm Assoc (2003). } \\
\text { 2014;54(4):415-8. }\end{array}$ & $\begin{array}{l}\text { To measure the impact of } \\
\text { ambulatory clinical } \\
\text { pharmacist integration in a } \\
\text { pediatric. } \\
\text { Primary care clinic on } \\
\text { vaccination error rates and } \\
\text { to evaluate missed } \\
\text { opportunities. }\end{array}$ & $\begin{array}{l}\text { A retrospective, quasi- } \\
\text { experimental review of } \\
\text { electronic medical records of } \\
\text { visit encounters during a 3- } \\
\text { month period compared } \\
\text { vaccine error rates and } \\
\text { missed opportunities } \\
\text { between two pediatric } \\
\text { residency primary care clinics. } \\
\text { The intervention clinic has a } \\
\text { full-time ambulatory clinical } \\
\text { pharmacist integrated into } \\
\text { the health care team. } \\
\text { Pharmacy services were not } \\
\text { provided at the comparison } \\
\text { clinic. A vaccine error was } \\
\text { defined as follows: doses } \\
\text { administered before } \\
\text { minimum recommended age, } \\
\text { doses administered before } \\
\text { minimum recommended } \\
\text { spacing from a previous dose, } \\
\text { doses administered } \\
\text { unnecessarily, live virus } \\
\text { vaccination administered too } \\
\text { close to a previous live } \\
\text { vaccine, and doses invalid for } \\
\text { combinations of these } \\
\text { reasons. }\end{array}$ & $\begin{array}{l}900 \text { encounters were randomly } \\
\text { selected and reviewed. The } \\
\text { error rate was found to be } \\
0.28 \% \text { in the intervention clinic } \\
\text { and } 2.7 \% \text { in the comparison } \\
\text { clinic. The difference in error } \\
\text { rates was found to be } \\
\text { significant ( } \mathrm{P}=0.0021 \text { ). The } \\
\text { number of encounters with } \\
\text { greater than or equal to one } \\
\text { missed opportunity was } \\
\text { significantly higher in the } \\
\text { comparison clinic compared } \\
\text { with the intervention clinic } \\
\text { ( } 29.3 \% \text { vs. } 10.2 \% \text {; } P<0.0001 \text { ). }\end{array}$ & $\begin{array}{l}\text { Pharmacist have the ability to } \\
\text { identify CDC scheduled } \\
\text { recommendation in pediatric } \\
\text { population. } \\
\text { Pharmacist can support } \\
\text { ambulatory clinics to increase } \\
\text { vaccination rates and decreases } \\
\text { the rates of missed } \\
\text { opportunities. }\end{array}$ \\
\hline
\end{tabular}


Table 2: Economics

\begin{tabular}{|c|c|c|c|c|}
\hline $\begin{array}{l}\text { Name of study and } \\
\text { description }\end{array}$ & Type of study / objectives & Methods & Results & Implications \\
\hline $\begin{array}{l}\text { Cost of Adult } \\
\text { vaccination in } \\
\text { Medical Settings and } \\
\text { Pharmacies: An } \\
\text { observational study }{ }^{17} \\
\text { Singhal PK et al. J } \\
\text { Manag Care Spec } \\
\text { Pharm. } \\
\text { 2014;20(9):930-6. }\end{array}$ & $\begin{array}{l}\text { Observational } \\
\text { retrospective study. } \\
\text { Objective: To examine } \\
\text { whether the direct } \\
\text { medical costs paid for } \\
\text { adult vaccination differ by } \\
\text { vaccination setting. }\end{array}$ & 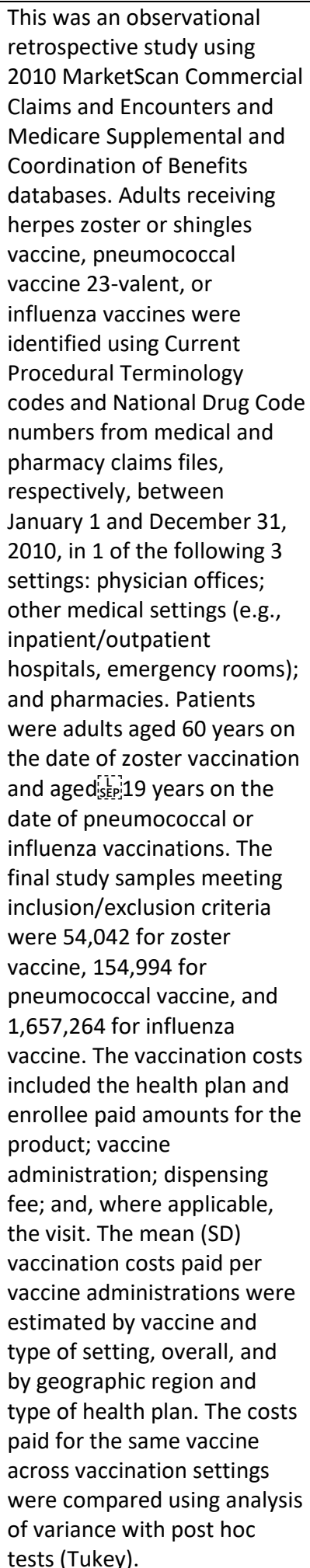 & 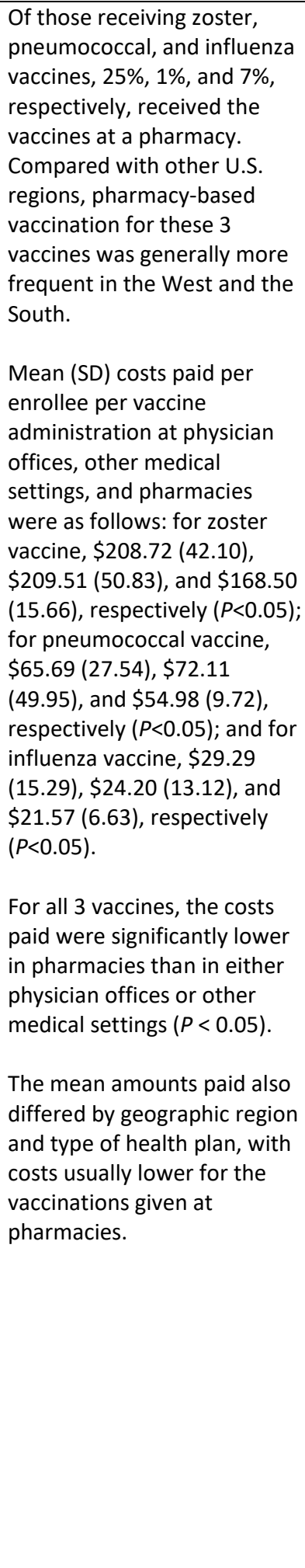 & $\begin{array}{l}\text { The average direct costs paid } \\
\text { per adult vaccination were } \\
\text { lower in pharmacies compared } \\
\text { with physician offices and other } \\
\text { medical settings by } 16 \%-26 \% \\
\text { and } 11 \%-20 \% \text {, respectively. } \\
\text { These results were mostly } \\
\text { consistent across geographic } \\
\text { regions and types of health } \\
\text { plans. } \\
\text { These data may help payers and } \\
\text { policymakers understand the } \\
\text { economic value of adult } \\
\text { vaccination in different settings, } \\
\text { especially in pharmacies. } \\
\text { The data may also help medical } \\
\text { or pharmacy insurance } \\
\text { providers understand the } \\
\text { economic value of expanding } \\
\text { the vaccination schedule } \\
\text { coverage to the pharmacy } \\
\text { setting. }\end{array}$ \\
\hline
\end{tabular}




\begin{tabular}{|c|c|c|c|c|}
\hline $\begin{array}{l}\text { Non Traditional } \\
\text { settings for influenza } \\
\text { of Adults } \\
\text { Costs and Cost } \\
\text { Effectiveness }^{18} \\
\text { Prosser LA et al. } \\
\text { Pharmacoeconomics. } \\
\text { 2008;26(2):163-78 }\end{array}$ & $\begin{array}{l}\text { To describe the cost of } \\
\text { vaccination in non- } \\
\text { traditional settings such } \\
\text { as pharmacies and mass } \\
\text { vaccinations clinics } \\
\text { Evaluate the projected } \\
\text { health benefits, cost and } \\
\text { cost effectiveness of } \\
\text { delivering influenza } \\
\text { vaccinations to adults of } \\
\text { varying ages and risk } \\
\text { groups in non-traditional } \\
\text { settings compared with } \\
\text { schedule doctor's office } \\
\text { visits in the United States. }\end{array}$ & $\begin{array}{l}\text { Evaluated cost of influenza } \\
\text { vaccinations in non- } \\
\text { traditional setting via detailed } \\
\text { telephone interviews with } \\
\text { vaccination clinics and } \\
\text { pharmacists who administer } \\
\text { vaccines } \\
\text { Decision tree used to } \\
\text { compare projected cost and } \\
\text { health benefits of receiving } \\
\text { an influenza vaccination from } \\
\text { non-traditional setting or } \\
\text { during schedule doctor office } \\
\text { visit with no vaccination. } \\
\text { Probabilities and cost (direct } \\
\text { and opportunity) for } \\
\text { uncomplicated influenza } \\
\text { illness, outpatient visits, } \\
\text { hospitalizations, deaths, } \\
\text { vaccination and vaccine } \\
\text { adverse events were derived } \\
\text { from primary data and } \\
\text { published and unpublished } \\
\text { articles. }\end{array}$ & $\begin{array}{l}\text { The mean cost ( } 2004 \text { values) } \\
\text { was lower in mass vaccination } \\
\text { (\$17.04) and pharmacy } \\
\text { (\$11.57) setting than in } \\
\text { scheduled office visits. } \\
\text { In non-traditional settings, } \\
\text { cost savings was projected for } \\
\text { healthy adults aged } \geq 50 \\
\text { years and for high-risk adults } \\
\text { of all ages. } \\
\text { For health adults } 18-49 \text { years } \\
\text { was cost effective, prevention } \\
\text { (\$US90) if vaccines delivered } \\
\text { in pharmacy setting, } \$ \text { US } 210 \\
\text { by mass vaccination, and } \\
\$ U S 870 \text { by scheduled doctor's } \\
\text { office visit. }\end{array}$ & $\begin{array}{l}\text { Vaccinations given in the } \\
\text { pharmacy setting is the most } \\
\text { cost effective way to administer } \\
\text { vaccines. } \\
\text { Vaccines given in pharmacy can } \\
\text { lower the cost to patients and to } \\
\text { health providers. }\end{array}$ \\
\hline
\end{tabular}


Table 3: Modified: National Association of Boards of Pharmacy: Survey of Pharmacy Law ${ }^{20}$

\begin{tabular}{|l}
\hline States \\
\hline Alabama, Arizona, California, \\
Colorado*, Delaware, District of \\
Columbia, Georgia, Idaho, Illinois, \\
Kentucky Louisiana, Maine*, \\
Mississippi, Missouri, Nebraska \\
Nevada*,New Hampshire, New Jersey, \\
New Mexico, Puerto Rico, South \\
Carolina, South Dakota,Tennessee, \\
Texas, Vermont ,Virginia
\end{tabular}

Alaska

Arkansas, Kansas, Oregon, West

Virginia

Connecticut,

Connecticut, Montana

Connecticut

Florida, Pennsylvania, West Virginia

Hawaii

Indiana

lowa, Colorado, Maine, Nevada, Ohio

Maryland

Massachusetts

Michigan

Minnesota

Montana

\section{List of Conditions Pharmacist Administer Vaccination}

Allowed to vaccinate with fewer restricted measures.

With board-approved collaborative practice protocol application.

Subject to vaccination protocol and completed course of study and training.

With restrictions. (FL - Consultant pharmacist in nursing home setting. Section 465.0125, F.S.)

Pursuant to protocol only. (MT - Institutional protocol.)

If pursuant to a collaborative practice protocol.

Pharmacists may vaccinate if they are certified by the board to administer injectables. (PA - if registered.)

Pursuant to a licensed medical - doctor's or osteopathic physician's order and collaborative agreement and authorization.

May administer vaccines under a drug order, prescription, or physician-approved protocol for influenza, shingles, pneumonia, tetanus, diphtheria, acellular pertussis, HPV, and meningitis.

Must be in accordance with a protocol.

IA-By written protocol pursuant to rules of the Board of Pharmacy or when specifically directed by the prescriber for an individual patient.

CO - Drug therapy management protocol.

MI- May administer cholesterol, blood glucose, and international ratio, hepatitis C.

NV - Protocol must be approved by the Board.

$\mathrm{OH}$ - Pharmacists and pharmacy interns may dispense naloxone pursuant to a physician-approved protocol. They are not specifically authorized to "prescribe," nor are they recognized as prescribers under Ohio law.) Statute allows pharmacists to administer influenza vaccines to individuals age nine and above; CDCrecommended vaccinations to individuals ages 11 to 18 with prescription; CDC-recommended vaccines and travel vaccines to adults under a protocol. Pharmacists may also administer self- administered drugs. Regulations pending. Registration with the Board is required.

Approved by Department of Public Health

Yes, if it has been delegated to them and they have the approved training. See Section 16215 of the Michigan Public Health Code on delegation.

Influenza to patients six years of age and older, all other vaccines to patients 13 years of age or older. Written protocol with a physician, APRN, or PA.

Pharmacists are authorized to prescribe and administer vaccines without a collaborative practice agreement in place for the following vaccines: influenza to those 12 years and older; pneumococcal polysaccharide, tetanus, and diphtheria to those 18 years and older; herpes zoster to those identified in Centers for Disease Control and Prevention guidelines; and in the event an adverse reaction, epinephrine or diphenhydramine to those 12 years and older. 


\begin{tabular}{|c|c|}
\hline New York & $\begin{array}{l}\text { May administer influenza, pneumococcal, herpes zoster, meningococcal, and tetanus, diphtheria, and } \\
\text { pertussis vaccines and drugs to treat reactions. }\end{array}$ \\
\hline North Carolina & $\begin{array}{l}\text { Influenza, pneumococcal, herpes, zoster, hepatitis B, meningococcal, tetanus-diphtheria, tetanus and } \\
\text { diphtheria toxoids and peruses, tetanus and diphtheria toxoids and acellular pertussis, tetanus toxoid, and } \\
\text { all other vaccinations recommended or required by the Centers for Disease Control and Prevention. }\end{array}$ \\
\hline North Dakota & When trained and authorized by Board. \\
\hline Ohio & Certain vaccines as listed in Ohio Revised Code $§ 4729.41$ and Board Rules. \\
\hline Oklahoma, & On prescriber's order. \\
\hline Rhode Island, West Virginia & Limited to certain adult vaccines. (RI - And flu vaccines for children ages nine and older.) \\
\hline Utah & $\begin{array}{l}\text { For inpatient pharmacist via institutional protocol only pursuant to the Division of Occupational and } \\
\text { Professional Licensing approved vaccine protocol. }\end{array}$ \\
\hline Washington & $\begin{array}{l}\text { The definition of the "practice of pharmacy" includes "drug administration." (WA - Definition also includes } \\
\text { the monitoring of drug therapy and use and the initiation or modification of drug therapy in accordance } \\
\text { with written guidelines or protocols in a previously established collaborative drug therapy agreement } \\
\text { between a pharmacist and practitioner authorized to prescribe drugs.) }\end{array}$ \\
\hline Washington & $\begin{array}{l}\text { If appropriately certified bases upon the } 12 \text {-hour Centers for Disease Control and Prevention training } \\
\text { program, the pharmacist can initiate vaccinations pursuant to a collaborative drug therapy agreement. }\end{array}$ \\
\hline Wisconsin & Yes, if requirements for coursework and insurance are met. \\
\hline Wyoming & Age 7 and older for certain vaccines. \\
\hline
\end{tabular}

